Annals of Glaciology $5 \quad 1984$

(c) International Glaciological Society

\title{
THE IGS SYMPOSIUM ON ICE AND CLIMATE MODELING:
}

\section{AN OVERVIEW}

by

\author{
Uwe Radok \\ (Cooperative Institute for Research in Environmental Sciences, Campus Box 449, University \\ of Colorado, Boulder, Colorado 80309, U.S.A.)
}

\section{ABSTRACT}

The Symposium on Ice and $\mathrm{Cl}$ imate Modeling was staged by the International Glaciological Society (IGS) with the co-sponsorship of the American Meteorological Society to bring glaciologists into direct contact with modelers of the Earth's climates during interglacials (such as the present) and glacial episodes. The purpose of mutual familiarization was served by reviews of the hierarchies which now exist for models of atmosphere, ocean, and climate. These reviews emphasized the actual or potential uses of ice data and parameterizations, and both general and specific aspects of coupling and sensitivity testing. The glaciologists in their turn reviewed the problems of exploring different ice forms and simulating their responses to $\mathrm{cl}$ imatic forcing. Interspersed with the didactic presentations important new results were reported. The most sign if icant concerned atmospheric concentrations of carbon dioxide deduced from ice core analyses, which were put into a wider context by a new interpretation of the ocean as a chemical system.

The presentations and discussions highlighted a wide range of problems ripe for collaborative study. Topics recommended for priority attention include contemporaneous changes in the properties of ice cores from Greenland and Antarctica, links between weather sequences and the stable isotope contents of polar precipitation, systematic intercomparisons of a wide range of model results, and the construction of intermediate-complexity sea-ice models for use in climate simulations.

\section{INT RODUCTION}

Any symposium, and especially an interdisciplinary one, needs to be judged from thematic, problematic, and analytic points of view. All of them involve the criteria of balance; in the present case, did the contributions provide a balanced cover of ice and its rightful place in climatic modeling? Has the balance of critical unsolved problems been identified and brought closer to interdiscipl inary cooperative solution? Did the analyses reported balance the sophistication of their ice models and inputs against that afforded to other components of the $\mathrm{cl}$ imate system?

An answer to the first of these broad questions could be formulated al ready with the extended abstracts. These also provided a good indication of the attention paid to the most critical unsolved problems of ice and $\mathrm{cl}$ imate which are complex and intractable almost by definition. On the other hand the question of balance in analys is and modeling involves sober judgements, which should not be attempted with any degree of conviction until the full work in question has been studied. For an overview to be published alongside the papers the appraisals of analytical balance will therefore only be prel iminary, at best.

\section{THE THEMATIC BALANCE OF THE ICE AND CLIMATIC MODEL-} ING SYMPOSIUM

The thematic composition of the symposium can be judged by grouping and counting the presentations under several broad headings, but some unscheduled poster contributions make it difficult to give precise numbers. Of a total of approximately 75 contributions, one-third were essentially diagnostic; they dealt with ice and climate data and used models to clarify and supplement the facts. Sea-ice data and models were addressed in nine contributions (12\%); anather five contributions $(17 \%)$ dealt more generally with ocean processes and models. Climate models including some form of ice were presented in twelve papers $(16 \%)$. In another twelve papers generalized ice sheets represented the principal model component, while specific ice-sheet regimes were treated in the remaining seven contributions (9\%).

This distribution shows a proper regard for reality, not only in the preponderance of data papers but also in the use of models for supplementing and interpreting the observations, especially for the ice sheets whose time scales make even a first description a distant goal. Some of the models which closed information gaps have also been used for reconstructions and extrapolations. Truly interactive simulations of the joint behavior of the ice sheets and other components of the $\mathrm{cl}$ imate system were addressed both by the papers centered on the ice sheets and those in which the ice plays a more peripheral role.

As regards sea ice, the symposium took place in a lull before the onslaught of new data and insights expected from the developing Marginal I ce Zone Experiment (MIZEX), which will further document and consolidate the role of sea ice as the most important interactive ice form of the climate system, at any rate on the priority time scales of the World Climate Research Program (WCRP). An only slightly weaker role could be claimed for the seasonal snow cover, and its absence from the contributions constituted a major thematic imbalance of the symposium. Another was the almost complete silence on progress with the very important 
absolute dating of core ice below the level of discernible annual layers.

\section{PROBLEMS ADDRESSED BY THE ICE AND CLIMATE MODELING} SYMPOSIUM

To meet the didactic aims of the symposium some of the modeling contributions did not present new findings but reviewed model aspects bearing on applications to, or use of, their ice components. With a similar purpose in mind, the purely glaciological contributors covered ice data, data archiving, and data interpretation problems as well as the full hierarchy of ice models. Each of the major ice forms (snow, sea ice, glaciers, ice shelves, ice sheets) received mention, in terms of their major processes (surface energy exchanges on snow, sea ice, and in and below glaciers; accretion/melting below ice shelves; heat conduction/advection in ice; deformation flow and basal sliding of ice sheets). The internal temperature field and ice-core properties were discussed as the principal climatic "indices" derivable from large ice masses. The ice-core presentations provided significant new facts about past $\mathrm{CO}_{2}$ concentrations (Stauffer and others, Raynaud and Barnola), which have helped to stimulate a major new assessment of the ocean as a chemical system (Broecker). I sotope data from lake (Siegenthaler and others), ocean (Imbrie) and ice (Lorius and others) cores made up the balance of paleoclimatic information presented, together with ancient $\mathrm{f}$ ir stumps defining past tree lines (Selsing and Wishman), pollen records (Webb), and astronomical data relating pole migration and irregularities in the timing of Babylonian eclipses to changing ice loads (Peltier).

The different ways in which all these data are being used help to group the remaining symposium contributions. One prominent feature of the isotope record, the recurrence of the last five major interglacials at roughly $100 \mathrm{ka}$ intervals, was addressed in one study as a problem of orbital period hunting (Imbrie). Other contributions constructed nonl inear oscillators with idealized ice sheets creating appreciable power at that frequency from orbital forcing (LeT reut and Ghil, Birchfield and Weertman), and one even suggested a mechanism that would account for the creation of the periodicity through the growth of very large ice sheets around $500 \mathrm{ka} B P$ (Watts and Hayder). This was supported implicitly by a study that has linked changes of the Antarctic ice through the intervention of sea-level changes to modeled orbitally-forced northern-hemisphere glaciations, and found the interglacial recurrence period to be a direct result of the size and polar location of the Antarctic ice (Budd and others).

However, the principal objective in that study and three others (Oerlemans, Alley and Whillans, Reeh), was to simulate a range of concurrent icesheet characteristics rather than just a series of (presumed) ice-volume changes. Somewhere in between the oscillators and the real istic model ice sheets one might place model studies reconstructing the history of a flowl ine in East Antarctica (Young and others) and of the dynamics of the West Antarctic ice streams discharging into Pine Island Bay and into the Ross I ce Shelf (Lingle and Clark, McInnes and Budd). A model simulation of ice-shelf dynamics (MacAyeal and Thomas) also belongs here, and at the same time formed a link to modeling studies concerned with ice in the oceans.

That 1 ink was made directly by a simulation of the processes below the Ross Ice Shelf flow (MacAyeal) suggesting incidentally how $\mathrm{CO}_{2}$-induced changes in the polar environment might impact the ice shelf by changes in the Antarctic sea ice. Such changes were described in observational terms (Zwally, Carsey), as a parameterization problem (Bratchie), and by full model simulations (Parkinson and Bindschadler, Walsh and $\mathrm{Hibler)}$. The importance of sea ice both for $\mathrm{cli}$ mate research and from operational points of view was underlined by regional Arctic sea-ice studies, (Kel iher and Foley, Pease and Overland) and by two independent and largely concordant assessments of the potential effects of projected Soviet river diversion schemes (Holt and others, Semtner).

That leaves the contributions concerned with $\mathrm{cli-}$ mate modeling per se. Review papers introduced the glaciologists to the hierarchies of energy-balance models (North, Schneider), atmospheric models (Thompson), and ocean models (Semtner), with special emphas is on models that might be conveniently coupled to glacial models. The problems of such (necessarily asynchronous) coupling were explained by Schneider who also described the pitfalls commonly encountered in sensitivity testing of factors entering the models with different time constants. A good example of such complications was provided by a study using a simple cl imate model to create a zonally-averaged ice sheet without recourse to arbitrarily imposed changes in equilibrium 1 ine altitude (Ledley). The climatic effects of the $18 \mathrm{ka}$ BP Climate Long-range Investigation Mapping and Prediction study (CLIMAP) ice sheet were established by Manabe and Broccoli and by Joussaume and others, while conditions during the last interglacial and a sequence of "snapshots" from the height of the glaciation through the hypsithermal of 9 to $6 \mathrm{ka}$ BP were presented by Kutzbach and Guetter and compared with the pollen record of Webb. A final group of contributions addressed more general problems of "ice-infected" climate modeling: how to modify an of ten-encountered excessive icealbedo feedback by allowing for the thermal inertia of the sea-ice ocean system (Robock) or for meridional heat transport (Molnar and Wang), and how to bypass the difficulty that in a global view the ice sheets are generated by energy fluxes below measurable threshold (Saltzman).

The last of these questions recalls an earlier dilemma (Loewe 1971) of how to account for the growth of the Wiscons in ice sheet from the reduced atmospheric water vapor available at lower temperatures. The modelers dealing in regional processes held that these and the atmosphere's power of concentration provides satisfactory explanations in both cases. On the other hand major unsolved problems emerged from discussions of the stable isotope record in ice and ocean cores. The earlier confidence in equating changes in $\delta^{18} 0 / 160$ or $\delta \mathrm{D} / \mathrm{H}$ directly with changes in climate or in ocean temperature or global ice volume has been replaced by a realization that the entire evaporation/sublimation history of the water vapor leaves its mark on the ultimate $\delta$ values of the deposited snow and that the $\delta$ values in ocean cores are significantly affected by the proportion of lowlatitude and high-latitude ice entering into any oceanic change. A model simulation of the changing 180 content of polar precipitation (Covey) favored a modified interpretation in terms of air-mass history while a diagnostic study of the same limited data set suggested an important role for the seasonal changing water-vapor source region (Bromwich). Against this the ice-core analysts continue to attribute ${ }^{18} 0$ variations primarily to changes in the local surface temperature. This unresolved disagreement poses a major problem of ice and climate in need of further interdisciplinary attention.

\section{THE ANALYTIC BALANCE IN ICE AND CLIMATE MODELING}

I ce and $\mathrm{Cl}$ imate modeling involves handling compl icated equations with terms of widely differing magnitude. Analytic balance can then be lost by dropping awkward small terms while retaining manageable ones of similar magnitude. In models an equivalent effect is produced by disregarding difficult processes and putting a disproportionate effort into representing others of equal import. A first appraisal of the various modeling contributions reveals a number of such imbalances but should be 1 imited to the most general aspects. 